Article

\title{
Functionalized Leather: A Novel and Effective Hazardous Solid Waste Adsorbent for the Removal of the Diazo Dye Congo Red from Aqueous Solution
}

\author{
Camila Clavijo and Johann F. Osma *i \\ CMUA. Department of Electrical and Electronics Engineering. Universidad de los Andes, \\ Carrera 1E \# 19A-40 Bogota, Colombia; mc.clavijo101@uniandes.edu.co \\ * Correspondence: jf.osma43@uniandes.edu.co
}

Received: 23 July 2019; Accepted: 9 September 2019; Published: 12 September 2019

check for updates

\begin{abstract}
The leather industry produces a high yield of solid hazardous wastes that generate a major impact on the environment. At the same time, the use of dyes by different manufacturing industries, including the footwear industry, creates large amounts of colored wastewater that is hard to treat. In this paper, potential adsorbents based on the functionalization of solid waste from leather in the removal of anionic dye Congo Red were studied. Twelve different functionalized adsorbents were analyzed in terms of dye removal. From those, the best adsorbents were characterized and tested to determine their life cycle, $\mathrm{pH}$ dependency and the resulting phytotoxicity of the treated dye baths. Different kinetic models were evaluated to describe this adsorption process. It was found that functionalized leather adsorbents presented multi-linearity behavior when removing Congo Red. Life cycle analysis showed that the adsorbents presented a high yield of absorption until the third cycle of operation, while phytotoxicity tested showed reductions up to $50 \%$ in the toxicity of the treated dye baths.
\end{abstract}

Keywords: leather; kinetics; dye adsorption; surface functionalization

\section{Introduction}

Wastewater pollution has become a serious problem worldwide. Specifically, wastewater from manufacturing industries that use large amount of dyes are generating abundant quantities of colored wastewater. Due to this, aquatic ecosystems have been severely impacted not only by the toxic, mutagenic and carcinogenic effects but also for the water quality due to changes in nutrients, inorganic sediments, and micropollutants [1-4]. Congo Red (CR) is an anionic dye that contains a benzidine compound (Figure 1), a carcinogenic and mutagenic substance. It is a toxic azo dye that can generate serious skin, genital, and eye irritations [5,6]. CR is most widely used due to its easy operation, low cost, and adhesion features. Due to its chemical structure, wherein aniline compounds are present, it is a harmful substance that seriously affects the environment [7].<smiles>Nc1c(N=Nc2ccc(-c3ccc(N=Nc4cc(S(=O)(=O)O[Na])c5ccccc5c4N)cc3)cc2)cc(S(=O)(=O)O)c2ccccc12</smiles>

Figure 1. Molecular structure of Congo Red (CR) dye. 
The removal of these dyes using chemical reagents and microorganisms is a difficult process due to its complex molecular structure and stability against these kind of degradations as they are designed to be resistant to degradation or vanishing by agents [2,4]. Thus, many types of removal technology have been developed, such as adsorption, membrane filtration, chemical precipitation, ion exchange, flocculation, ultrafiltration, photocatalysis, ozonation techniques, and decomposition by microorganisms [2,8-17]. However, adsorption method has proven to be a promising method due to its efficiency, relatively low cost, reusability, and easy operation $[9,18]$. Congo red adsorption has been reported with adsorbents such as activated carbon with a removal efficiency of about $100 \%$ [19], activated carbon prepared from Aloe Vera leaves with a performance of almost 100\% [20], jujuba seeds with a dye removal of $88 \%$ [21], roots of Eichhornia crassipes with $96 \%$ [22], and montmorillonite clay with $85 \%$ [23]. The use of solid waste as an adsorbent material has been extensively studied, however, such hazardous waste materials as leather have rarely been applied to this purpose. Leather can be functionalized to complete this and other tasks; but at present time, only some functionalizations have been reported for other uses. Studies reported leather functionalization with polysiloxanes for water repellency, leather finishing and preparation method; while, silanes have been used for antimicrobial activity and tanning [24-28].

The leather industry has become important in the economy of different countries but the impact on the environment by solid wastes has become overwhelming $[29,30]$. Destining this solid waste as adsorbent results as an interesting way to counteract the environmental effect produced by its own industry and also reuse the material in a cost-effective way. None of the above mentioned adsorbents can be considered as the reuse of a hazardous residual material with respect to the tanned leather residues from the footwear industry, as used in this work, thus shedding light on the use of these hazardous residues as a promising adsorbent material, especially in countries with a large leather tanning industry, that also produces a high yield of wastewater containing dyes.

In the present study, a new potential bio-adsorbent, capable of removing the anionic dye Congo Red (CR) from aqueous solution, was developed using solid wastes from the leather industry. However, leather by itself is not a suitable adsorbent material for this purpose; therefore, 12 different surface functionalizations were carried out in two types of milled leather to improve the adsorption capacity of this solid waste. The effect of $\mathrm{pH}$ and the life cycle of the produced adsorbents were analyzed, as well as phytotoxicity test of the treated dye baths.

\section{Materials and Methods}

\subsection{Reagents}

Congo Red (CR) (Figure 1) was purchased from Sigma-Aldrich and was used without any further purification. (3-Aminopropyl) triethoxysilane (APTES) was obtained from Chem Xinglu chemical (China), tetraethoxysilane (TEOS) from Yeshun (China) and dodecyltrimethoxysilane (DODEC) from LD Chem (China).

\subsection{Adsorbents}

Leather residues from footwear industry were obtained from Industrias Wilches S.A. (Bogota, Colombia), cut into pieces and then milled (particle size about $3.4 \mathrm{~mm}$ for L1 and $6.8 \mathrm{~mm}$ for L2) in a D6450 Hanau 11 (Condux, Maschinenbau GmbH\& Co, Hanau, Germany). The pieces were washed using a cloth filter in order to remove any adhering dirt and air dried at room temperature for 48 hours. L1 particles showed a mean surface area of $332.73 \mathrm{~mm}^{2}$ and a mean pore area of $2.84 \mathrm{~mm}^{2}$. L2 particles showed a mean surface area of $359.06 \mathrm{~mm}^{2}$ and a mean pore area of $1.41 \mathrm{~mm}^{2}$.

\subsection{Surface Functionalization}

Twelve different functionalization processes were conducted at room temperature by adding $3 \mathrm{~g}$ of L1 or L2 substrate in $15 \mathrm{ml}$ falcon tubes containing $10 \mathrm{ml}$ of MilliQ water with $\mathrm{NaOH}$ drops until 
reaching $\mathrm{pH} 13$ as basal mixture. Then, $300 \mu \mathrm{l}$ of APTES, TEOS or DODEC were added to the basal mixture to carry out the functionalization of the substrate. Half of the samples were later treated with $300 \mu$ of glutaraldehyde to obtain the 12 different types of functionalization. All processes were left overnight and then, functionalized substrates were placed inside 1-inch PVC tubes and then dried at temperature room for $48 \mathrm{~h}$. Tubes were closed at both ends using a mesh to contain the functionalized substrate that worked as adsorbents for further tests. As controls, non-functionalized substrates (L1 and L2) were used in all tests. The twelve types of adsorbents and the two controls with their corresponding code names are showed in Figure 2. Functionalizations were characterized using FTIR and SEM imaging.

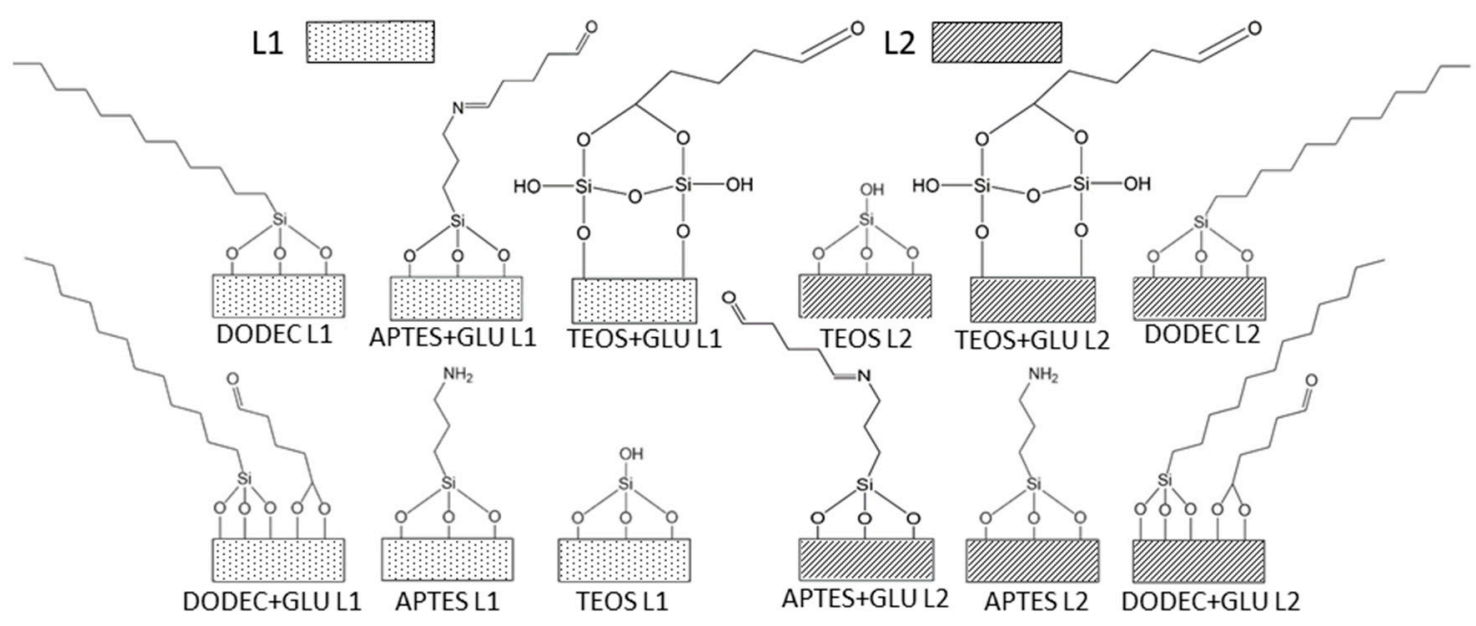

Figure 2. Surface functionalization representations of the adsorbents.

\subsection{Retention Time Test of Adsorbents}

First, $8 \mathrm{ml}$ of MilliQ water was added on top of each adsorbents to determine their adsorption capacity and retention time. Then, capacity was calculated by measuring the dried weight of the adsorbent and its latter wet weight, while retention time was determined as the time taken by the first drop of water that came out from the adsorbent.

\subsection{Dye Adsorption Tests}

Adsorbents were placed into beakers containing $60 \mathrm{mg} / \mathrm{l}$ of CR dye in MilliQ water at $\mathrm{pH}$ 4, adjusted by adding few drops of $2 \mathrm{M} \mathrm{H}_{2} \mathrm{SO}_{4}$, for 240 minutes at room temperature and under static conditions. Changes in absorbance were continuously monitored spectrophotometrically (ThermoFisher Scientific, Waltham, MA, USA) at a wavelength of $497 \mathrm{~nm}$, which corresponds to the maximum adsorption peak of CR. CR removal was expressed in terms of percentage.

\subsection{Effect of $p H$ on Dye Adsorption}

The two adsorbents that presented the highest CR removal from the previous test, were tested at different $\mathrm{pH}$ values from 3.0 to 8.0 , using phosphate citrate buffer, with the same concentration of $\mathrm{CR}$ $(60 \mathrm{mg} / \mathrm{l})$ for five days. Changes in absorbance were determined spectrophotometrically by measuring the area under the plot from 400 to $700 \mathrm{~nm}$. CR removal was expressed in terms of percentage. The amount of dye removed on the adsorbents was calculated as:

$$
q=\frac{\left(C_{i}-C\right) \times V}{m}
$$


where $q$ is the adsorption capacity $\left(\mathrm{mg} \mathrm{g}^{-1}\right) ; C_{i}$ is the initial dye concentration $\left(\mathrm{mg} \mathrm{L}^{-1}\right) ; C$ is the dye concentration at time $\mathrm{t}\left(\mathrm{mg} \mathrm{L}^{-1}\right)$, respectively; $m(\mathrm{~g})$ is the mass of adsorbent; and $V(\mathrm{~L})$ is the dye solution volume.

\subsection{Life Cycle Determination}

The two adsorbents that presented the highest $\mathrm{CR}$ removal were reused again at its optimum $\mathrm{pH}$ ( $\mathrm{pH} 3$ ) for four more cycles to determine its life cycle. Color removal was measured at the beginning and in the end of each five-day cycle, for a total of 25 days of exposure. After each cycle the adsorbent was removed from the beaker, left it to dry at room temperature for two days, and introduced into a fresh CR preparation for the next five-day cycle.

\subsection{Phytotoxicity Test}

Sawgrass seeds (Fercon, Cali, Colombia) placed on paper filters inside petri dishes, were exposed to untreated and treated dye baths samples obtained from the dye adsorption experiments. MilliQ water was used as the positive control, while untreated $60 \mathrm{mg} / \mathrm{L} \mathrm{CR}$ samples were used as negative controls. Three replicates were carried out at per each $\mathrm{pH}$ value and per type of adsorbent. Seeds were grown for five days under static conditions and light cycles of eight hours. Phytotoxicity was determined by counting the germinated seed and the stem length.

\subsection{Microscopic Examination}

Adsorbent samples before and after being exposed to dye baths were sputter with graphite and examined with a JEOL JSM 6490-LV (SEM) at 20kV (Universidad de los Andes, Bogota, Colombia).

\section{Results and Discussion}

\subsection{Surface Functionalization}

Adsorbents were functionalized as proposed in Figure 3. Some studies have reported similar mechanisms [31-34]. For the characterization of adsorbents, SEM images and Fourier transform infrared (FTIR) spectra were recorded (ALPHA, BRUKER, Billerica, MA, USA) for the functionalized adsorbents and for the untreated leather.

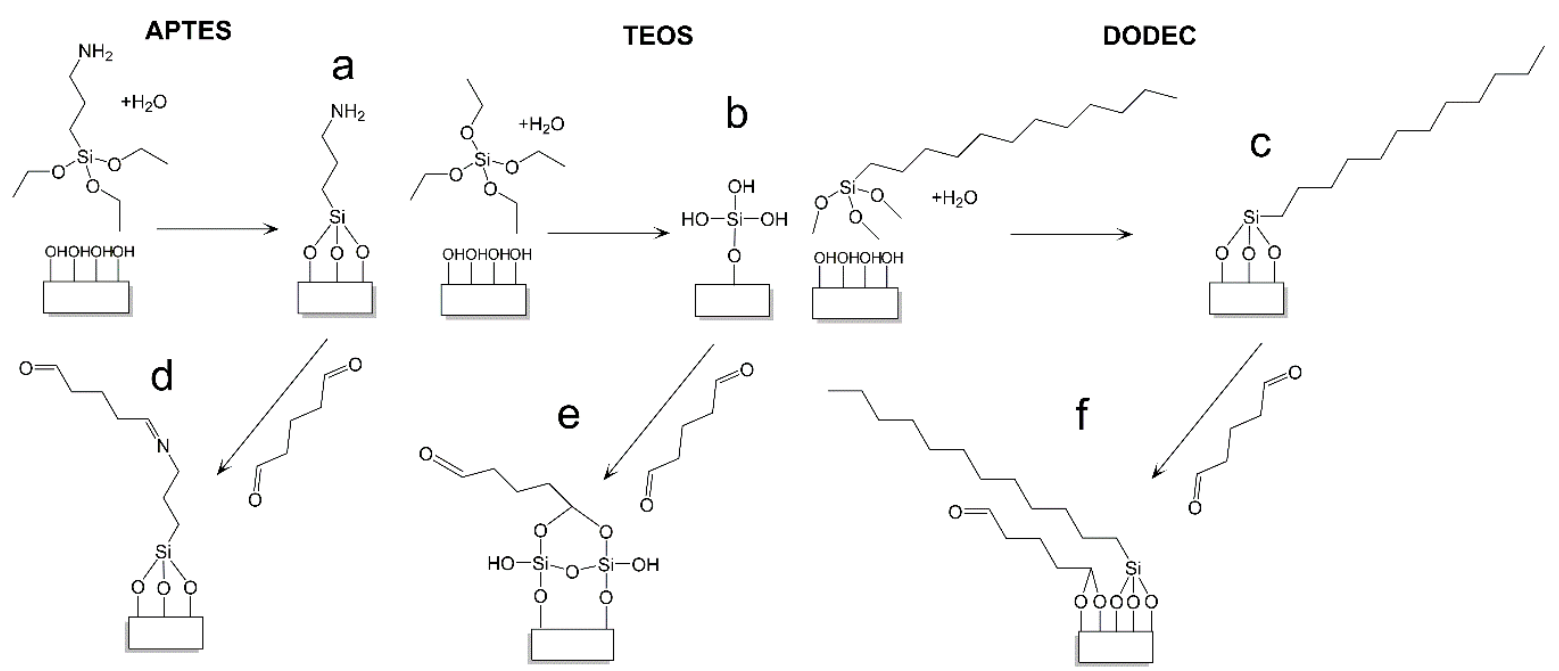

Figure 3. Proposed functionalization mechanism for each type of silane. (a) APTES, (b)TEOS, (c) DODEC, (d) APTES + glu, (e) TEOS + glu and (f) DODEC + glu.

Figure 4 shows the spectra for the presence of each silane and main groups were labeled. Main common groups between the substrates are $\mathrm{CH}_{2}, \mathrm{C}=\mathrm{O}$, SiOSi. However, each substrate has more 
specific groups in each spectrum. For APTES, $\mathrm{OH}, \mathrm{NH}_{2}, \mathrm{SH}$ and $\mathrm{OH}$ (out of plane) and $\mathrm{C}-\mathrm{N}$ groups are present. For TEOS, groups like $\mathrm{SiOH}$ and for DODEC, groups as $\mathrm{C}-\mathrm{H},-\mathrm{OH}$ and $\mathrm{C}-\mathrm{O}$ are present. In the cases for the functionalizations including silanes and glutaraldehyde, there was a common group with a characteristic peak at approximately $750 \mathrm{~cm}^{-1}$. It should be noted that since the untreated leather was tanned, its spectrum revealed the presence of amino and aldehyde groups.

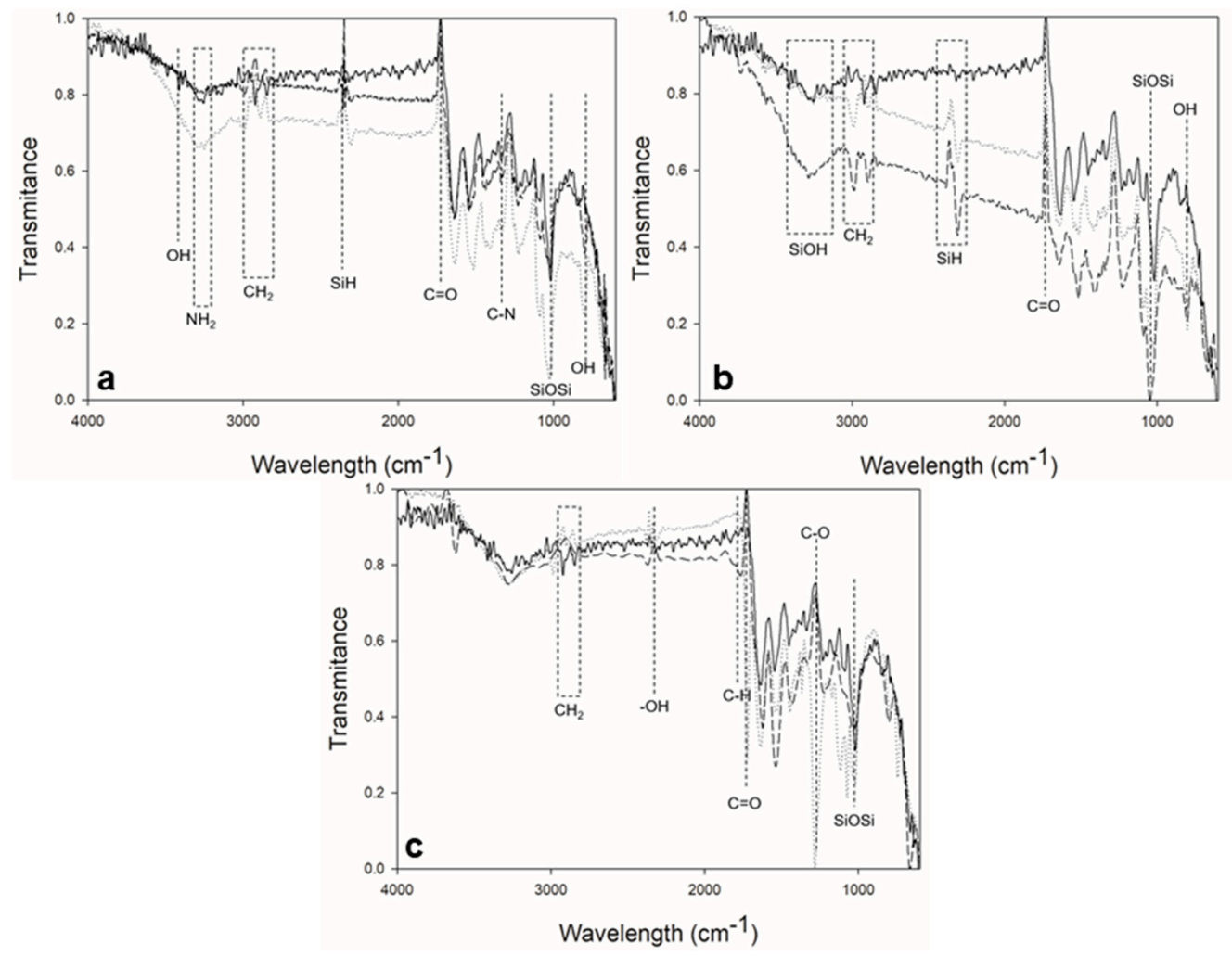

Figure 4. FTIR spectra of APTES (a), TEOS (b) and DODEC (c) for Leather (-), Leather functionalized with a silane $(\cdots)$ and leather functionalized with a silane and glutaraldehyde (--).

Figure 5 shows the SEM images of untreated leather (a), functionalized leather with silanes (b, c and $d$ ) and functionalized leather with silanes and glutaraldehyde (e, f and $g$ ). Morphological changes between functionalization steps can be observed, while smoother surfaces can be appreciated after adding glutaraldehyde, probably due to the cross-linking properties of the molecule.

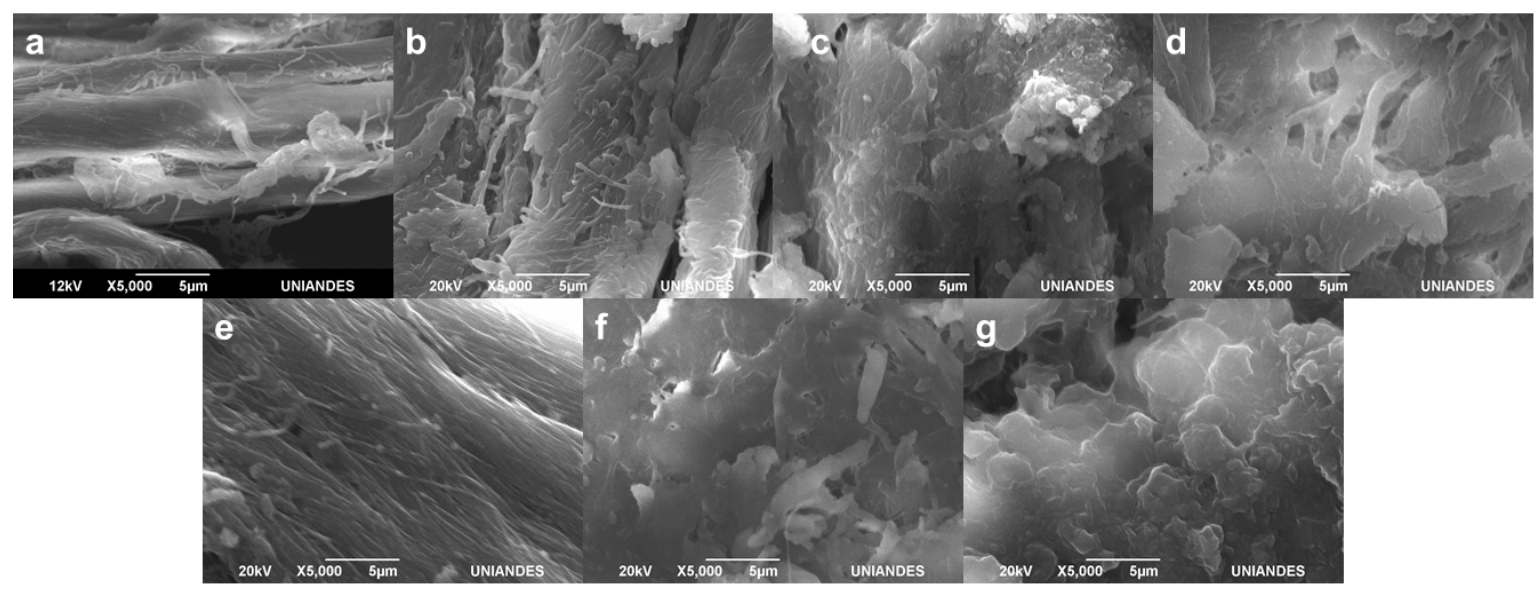

Figure 5. SEM photographs of (a) untreated leather, (b) APTES, (c) TEOS, (d) DODEC, (e) APTES+glu, (f) TEOS+glu and (g) DODEC+glu. 


\subsection{Retention Time Tests of Adsorbents}

The adsorption capacity of each adsorbent was calculated using the retention by adding $8 \mathrm{ml}$ of water on top of each adsorbent. Figure 6 shows the ability of each adsorbent to filter and retain water. In general, the retention time of L2 adsorbents was higher than those of the same type based on L1. However, the highest retention times were shown by adsorbents based on the surface functionalization of APTES for both L1 and L2, and surface functionalizations using glutaraldehyde for all silanes but only for L2. These results suggested that the retention time is highly dependent on the size of the particle material, and that the glutaraldehyde could play the role of crosslinking when the particle size was small enough.

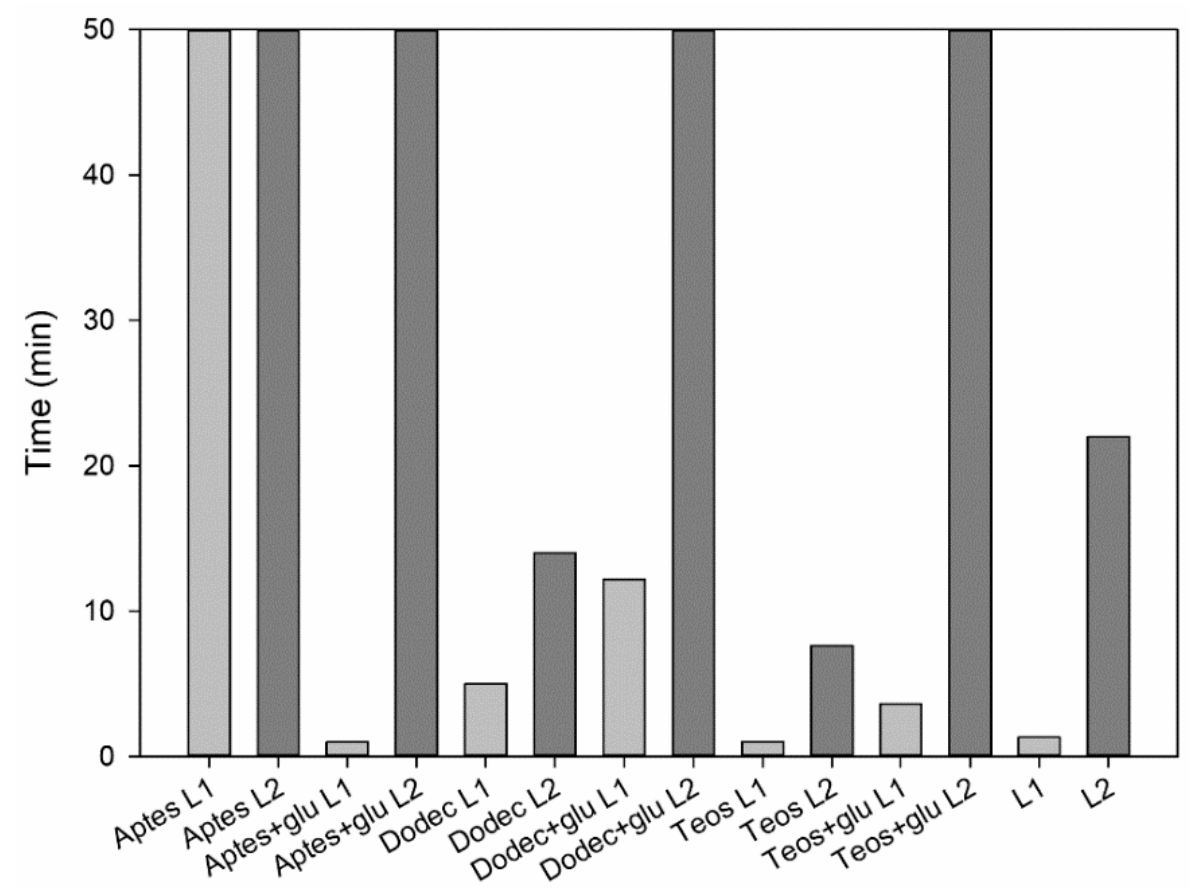

Figure 6. Filtration and retention of water by the adsorbents.

\subsection{Effect of The Adsorbents on Dye Removal}

Figure 7 shows the percentage of dye removed by each adsorbent. In general, all functionalizations presented a higher dye removal than the controls. The presence of glutaraldehyde on the adsorbents did not promote the dye removal neither for L1 nor L2. The functionalizations based only on APTES, presented the highest dye removal, between $25 \%$ and $30 \%$ in four hours, which is clearly superior to the rest of adsorbents that presented dye removal of less than 15\%. Therefore, APTES L1 and APTES L2 adsorbents were selected for the further tests and characterizations.

\subsection{Dye Absorption on Different $p H$}

The two selected adsorbents were exposed to $60 \mathrm{mg} / \mathrm{L} \mathrm{CR}$ at $\mathrm{pH} 3-8$ for more than 85 hours. Dye removal was monitored during the experiment to evidence the effect of $\mathrm{pH}$ on both the aqueous chemistry and the surface binding-sites of the adsorbent [34]. The effect of the adsorbents at different $\mathrm{pH}$ are shown in Figure 8. The percentage of dye removed increased as the $\mathrm{pH}$ decreased. The reaction equilibrium was reached at a time of 20 hours except for test at $\mathrm{pH} 5$, that took 34 hours, $170 \%$ times higher. Adsorption processes carried out at $\mathrm{pH}$ equal of higher than six did not presented significant results, showing a $\mathrm{pH}$ barrier for these mechanisms. This could be because the adsorption process was driven by the electrostatic attraction between adsorbed $\mathrm{H}+$ groups and the anionic dye [6,35], and since L1 and L2 are negatively charge, a repulsion between the anionic dye and the substrate 
surface will be boosted with an increase in $\mathrm{pH}$, thus, decreasing the binding strength. These results are in agreement with those reported by Saleh et al. and Jagusiak et al. [1,36].

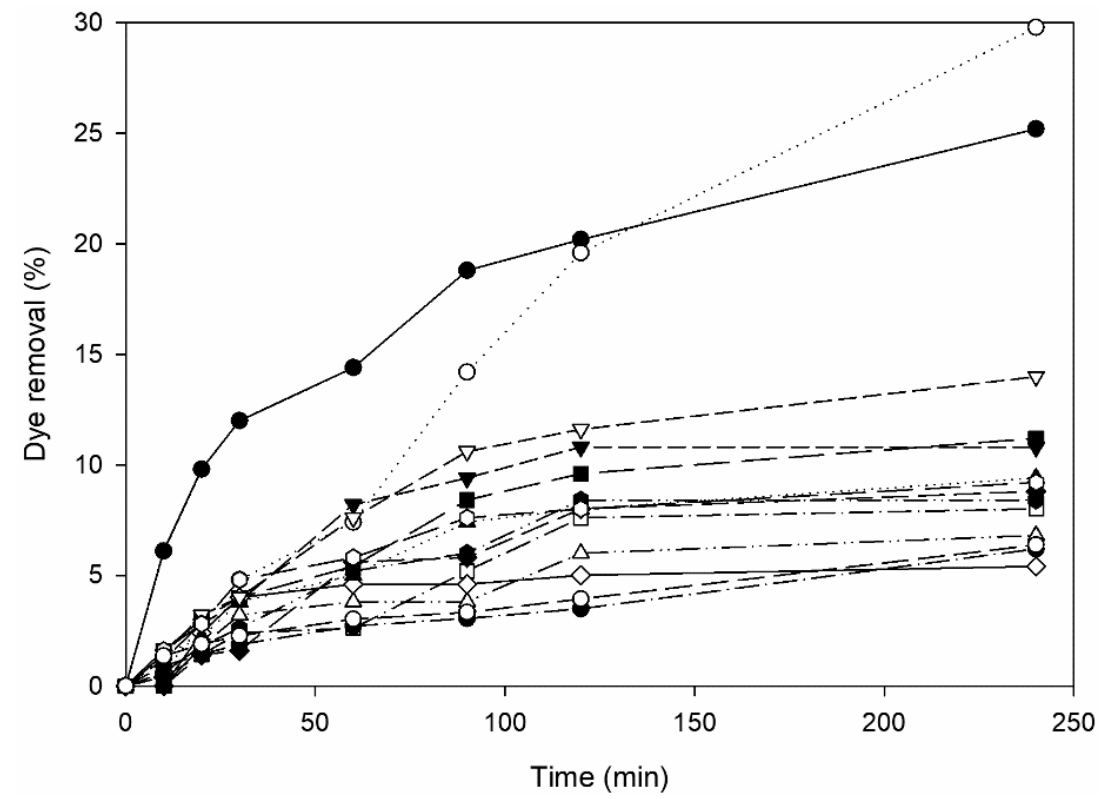

Figure 7. Percentage of CR removal in aqueous solution for APTES L1 (-•-); APTES L2 $(\cdots \circ \cdots)$;

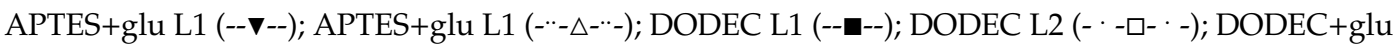

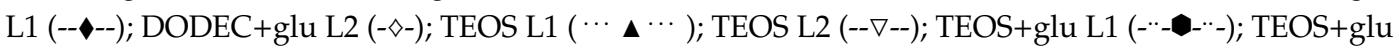
L2 (--○--); L1 (- - -- '-); L2 (--○--).

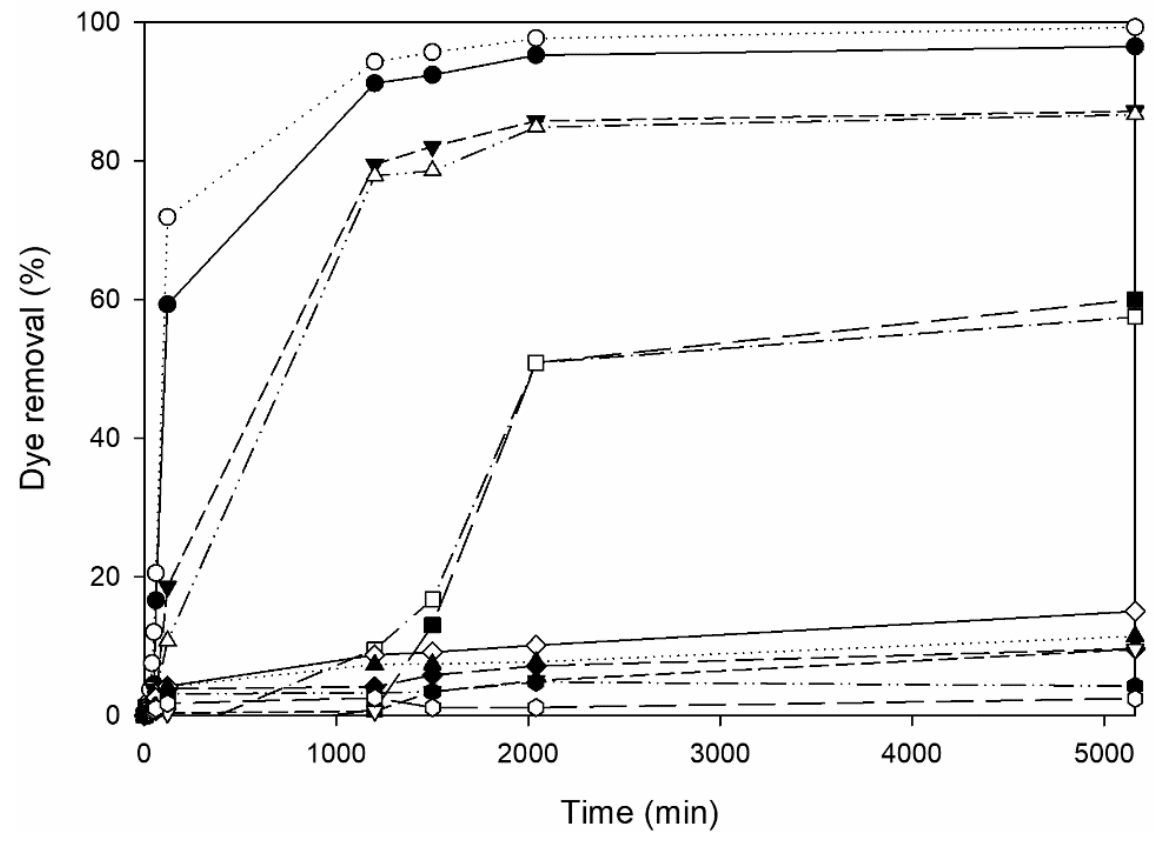

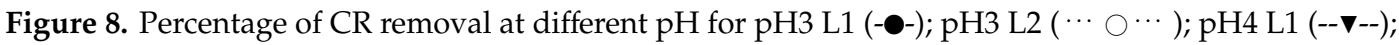

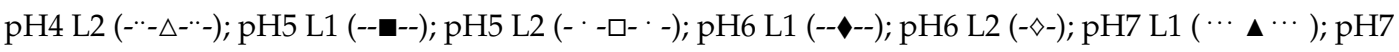
L2 (-----); pH8 L1 (------); pH8 L2 (--口--). 


\subsection{Langmuir and Freundlich Isotherm Models}

A Langmuir linear model characterizes the generation of a monolayer adsorbate in the surface of the absorbent. It is expressed by the following equation:

$$
\frac{1}{q_{e}}=\left(\frac{1}{K_{L} Q_{m} C_{e}}\right)+\frac{1}{Q_{m}}
$$

where $q_{e}$ is the quantity of dye adsorbed at equilibrium $\left(\mathrm{mg} \mathrm{g}^{-1}\right)$; Ce $\left(\mathrm{mg} \mathrm{g}^{-1}\right)$ is the unadsorbed adsorbate concentration in solution, $K_{L}$ is the Langmuir isotherm constant $\left(\mathrm{L} \mathrm{mg}^{-1}\right)$ and $Q_{m}$ is the maximum capacity of monolayer coverage $\left(\mathrm{ml} \mathrm{g}^{-1}\right)$.

The main feature of this model is expressed as a constant called the separation factor. It is dimensionless and is defined as:

$$
R_{L}=\frac{1}{1+K_{L} \times C_{O}}
$$

where $C_{O}\left(\mathrm{mg} \mathrm{L}^{-1}\right)$ is the initial concentration. The value of this separation factor indicates the adsorption nature as favorable $\left(0<R_{L}<1\right)$, unfavorable $\left(R_{L}>1\right)$ or linear $\left(R_{L}=1\right)$. Table 1 presents the values of the different parameters indicating that the adsorption isotherms were favorable, $R_{L}<1$ but close to the unity; therefore, related to reversible cases.

Table 1. Langmuir Isotherm data for the two types of substrates.

\begin{tabular}{cccc}
\hline L1 & \multicolumn{2}{c}{ L2 } \\
\hline Isotherm Parameters & Values & Isotherm Parameters & Values \\
\hline$Q_{m}\left(\mathrm{mg} \mathrm{g}^{-1}\right)$ & 3831 & $Q_{m}\left(\mathrm{mg} \mathrm{g}^{-1}\right)$ & 746.27 \\
$K_{L}\left(\mathrm{~L} \mathrm{mg}^{-1}\right)$ & 0.001659 & $K_{L}\left(\mathrm{~L} \mathrm{mg}^{-1}\right)$ & 0.000080 \\
$R_{L}$ & 0.9095 & $R_{L}$ & 0.9952 \\
\hline $\mathrm{R}^{2}$ & 0.99 & $\mathrm{R}^{2}$ & 0.99 \\
\hline
\end{tabular}

Freundlich linear model describes the adsorption isotherm for heterogeneous surfaces. Its linear form is expressed as:

$$
\log \left(q_{e}\right)=\log K_{f}+\frac{1}{n} \log C_{e}
$$

where $K_{f}\left(\mathrm{~L} \mathrm{~g}^{-1}\right)$ is the Freundlich constant and $n\left(\mathrm{~g} \mathrm{~L}^{-1}\right)$ is the Freundlich exponent, describing the adsorption intensity. Table 2 shows values of $n>1$, related to L-type isotherms, meaning that the relative adsorption decreases while the concentration of CR increases. Also, as the data fitted into this model (R2), it means that there was heterogeneity in the adsorbent surface [36].

Table 2. Freundlich isotherm data for the two types of substrates.

\begin{tabular}{cccc}
\hline \multicolumn{1}{c}{ L1 } & \multicolumn{2}{c}{ L2 } \\
\hline Isotherm Parameters & Values & Isotherm Parameters & Values \\
\hline$n$ & 1.015 & $n$ & 1.003 \\
$K_{f}$ & 0.30 & $K_{f}$ & 0.30 \\
$\mathrm{R}^{2}$ & 0.99 & $\mathrm{R}^{2}$ & 0.99 \\
\hline
\end{tabular}

\subsection{Kinetics of the Adsorption Process}

Two different kinetic adsorption models were analyzed to determine which one described better the experimental adsorption processes. A pseudo-first order model is expressed as follows:

$$
\log \left(q_{e}-q_{t}\right)=\log q_{e}-K_{1} \frac{t}{2.303}
$$


where $q_{e}$ is the quantity of dye adsorbed at equilibrium $\left(\mathrm{mg} \mathrm{g}^{-1}\right), q_{t}\left(\mathrm{mg} \mathrm{g}^{-1}\right)$ is the quantity of dye adsorbed at time $t(\mathrm{~min})$, and $K_{1}$ is the rate constant $\left(\mathrm{g} \mathrm{mg}^{-1} \mathrm{~min}^{-1}\right)$. As shown in Figure 9 and Table 3 , with a mean $R^{2}$ of 0.8085 , some samples did not display good linearity.

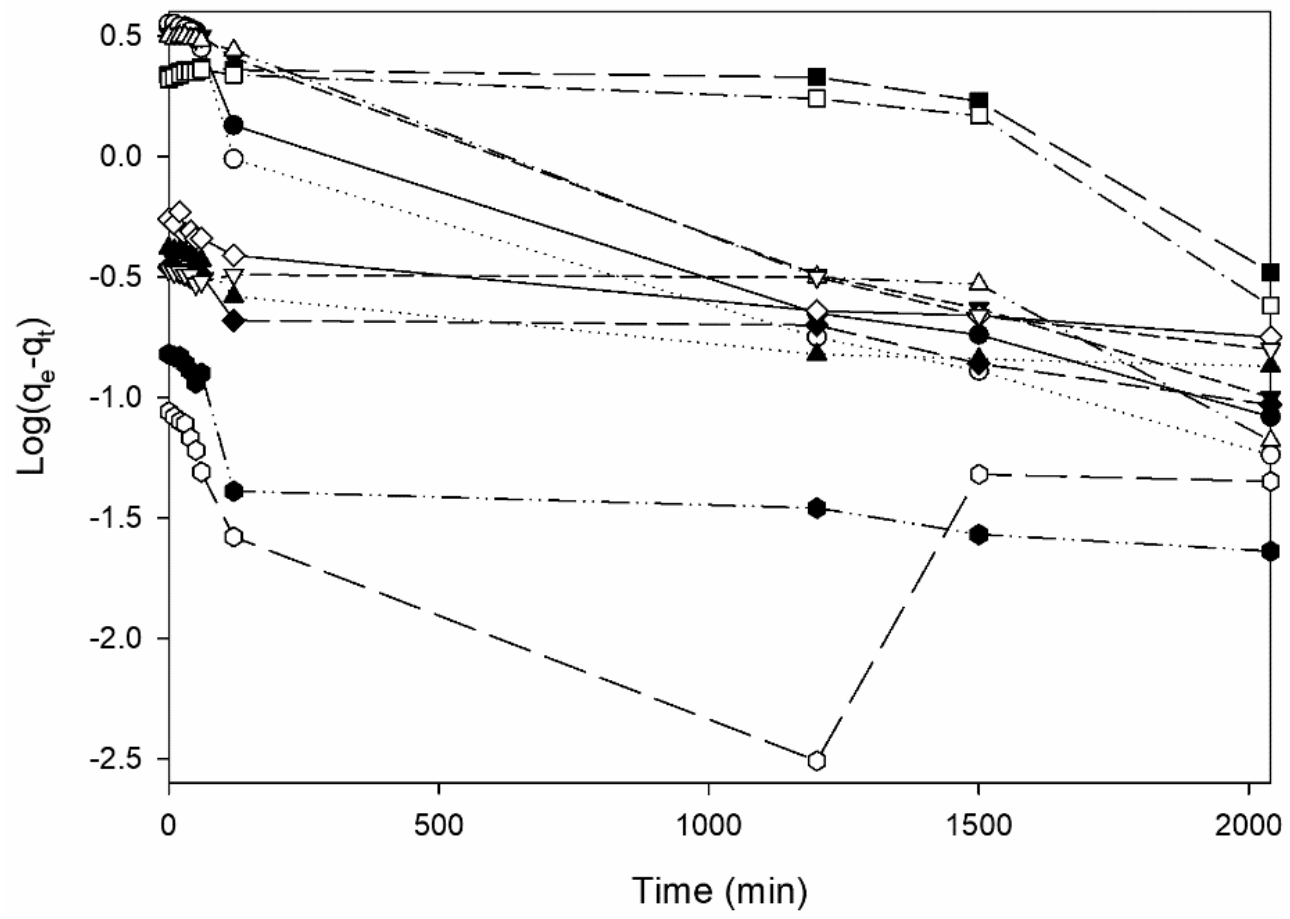

Figure 9. Pseudo-first order adsorption kinetics of CR for pH3 L1 (-๑); pH3 L2 ( $\cdots \bigcirc \cdots)$; pH4 L1

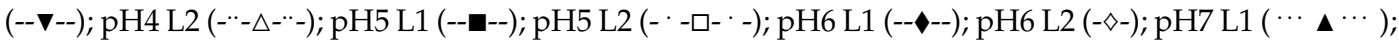

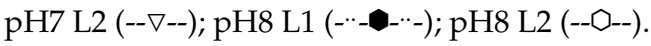

Table 3. Pseudo-first order data for different $\mathrm{pH}$ and two types of substrates.

\begin{tabular}{|c|c|c|c|c|c|c|c|c|c|c|c|c|}
\hline \multirow{2}{*}{ Parameters } & \multicolumn{6}{|c|}{ L1 } & \multicolumn{6}{|c|}{$\mathbf{L} 2$} \\
\hline & $\mathrm{pH} 3$ & $\mathrm{pH} 4$ & pH5 & $\mathrm{pH} 6$ & pH7 & pH8 & pH3 & pH4 & pH5 & $\mathrm{pH} 6$ & pH7 & pH8 \\
\hline$q_{e}$ calculated & 3.18 & 3.30 & 2.44 & 0.32 & 0.38 & 0.12 & 3.04 & 3.32 & 2.38 & 0.50 & 0.33 & 0.06 \\
\hline$K_{1}$ calculated & 0.002 & 0.002 & 0.001 & 0.001 & 0.001 & 0.001 & 0.002 & 0.002 & 0.001 & 0.001 & 0.000 & 0.001 \\
\hline$q_{e}$ experimental & 0.17 & 0.48 & 1.49 & 3.31 & 3.23 & 3.48 & 0.11 & 0.54 & 1.57 & 3.11 & 3.25 & 3.56 \\
\hline $\mathrm{R}^{2}$ & 0.97 & 1.00 & 0.61 & 0.90 & 0.91 & 0.79 & 0.95 & 0.99 & 0.68 & 0.94 & 0.76 & 0.19 \\
\hline
\end{tabular}

The adsorption process was evaluated according to the Pseudo-second order, expressed by the following equation:

$$
\frac{t}{q_{t}}=\frac{1}{k_{2} q_{e}^{2}}+\frac{t}{q_{e}}
$$

where $K_{2}$ is the rate constant $\left(\mathrm{g} \mathrm{mg}^{-1} \mathrm{~min}^{-1}\right)$; $\mathrm{q}_{\mathrm{e}}$ is the quantity of dye adsorbed at equilibrium $\left(\mathrm{mg} \mathrm{g}^{-1}\right)$ and $\mathrm{qt}\left(\mathrm{mg} \mathrm{g}^{-1}\right)$ is the quantity of dye adsorbed at time $t(\mathrm{~min})$. As shown in Table 4 and Figure 10, the experimental data fitted with a mean $\mathrm{R}^{2}$ of 0.986 and the calculated kinetic model constants towards a pseudo-second order kinetics model. 
Table 4. Pseudo-second order data for different $\mathrm{pH}$ and two types of substrates.

\begin{tabular}{cccccccccccccc}
\hline \multirow{2}{*}{ Parameters } & \multicolumn{1}{c}{ L1 } & \multicolumn{1}{c}{ L2 } \\
\cline { 2 - 13 } & $\mathbf{p H 3}$ & $\mathbf{p H 4}$ & $\mathbf{p H 5}$ & $\mathbf{p H 6}$ & $\mathbf{p H 7}$ & $\mathbf{p H 8}$ & $\mathbf{p H 3}$ & $\mathbf{p H 4}$ & $\mathbf{p H 5}$ & $\mathbf{p H 6}$ & $\mathbf{p H 7}$ & $\mathbf{p H 8}$ \\
\hline$q_{e}$ calculated & 0.18 & 0.48 & 1.54 & 3.32 & 3.24 & 3.49 & 0.11 & 0.55 & 1.62 & 3.12 & 3.26 & 3.56 \\
$K_{2}$ calculated & 0.00 & 0.12 & 1.18 & 5.50 & 5.24 & 6.07 & 0.01 & 0.30 & 2.63 & 1.70 & 12.93 & 19.70 \\
$q_{e}$ experimental & 0.17 & 0.48 & 1.49 & 3.31 & 3.23 & 3.48 & 0.11 & 0.54 & 1.57 & 3.11 & 3.25 & 3.56 \\
\hline $\mathrm{R}^{2}$ & 0.97 & 0.99 & 0.96 & 1.00 & 1.00 & 1.00 & 0.96 & 0.99 & 0.97 & 1.00 & 1.00 & 1.00 \\
\hline
\end{tabular}

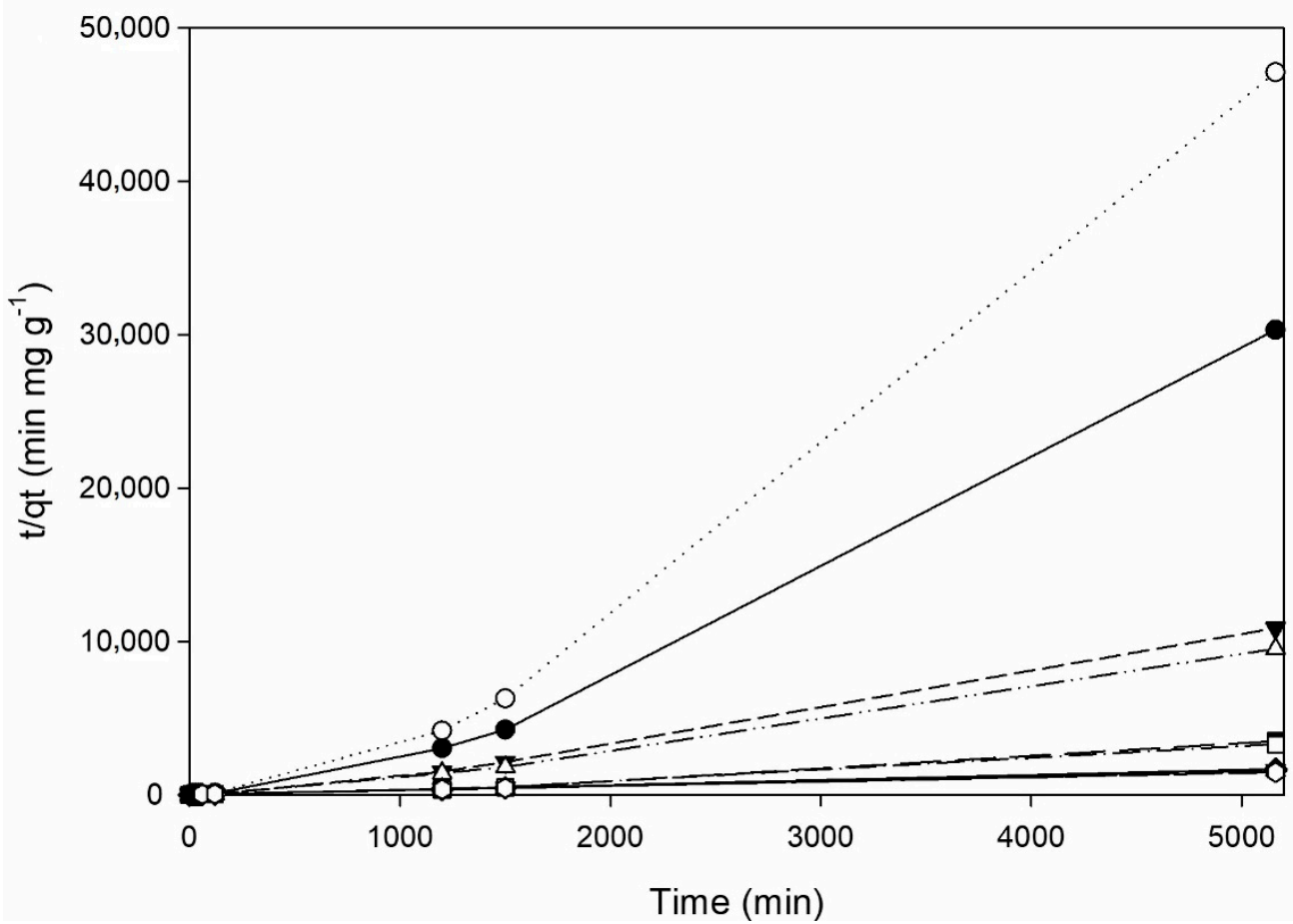

Figure 10. Pseudo-second order adsorption kinetics of CR for pH3 L1 (-๑); pH3 L2 ( $\cdots \bigcirc \cdots)$; pH4

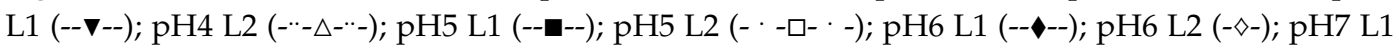

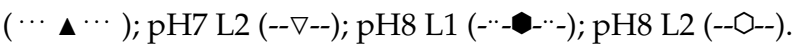

\subsection{Intra-Particle Diffusion Study}

Intra-particle model was also used to analyze the experimental data of the dye adsorption processes. Assuming that the rate was controlled by pore size and intra-particle diffusion, under static conditions, the amount of dye adsorbed $\left(q_{t}\right)$ is proportional to the square root of time $\left(t^{1 / 2}\right)$, as per the relationship given by Weber and Morris [37], and expressed in the following equation:

$$
q_{t}=k_{p} t^{1 / 2}
$$

where $q_{t}\left(\mathrm{mg} \mathrm{g}^{-1}\right)$ is the dye adsorbed at time $t(\mathrm{~min})$ and $k_{p}$ is the intra-particle diffusion rate constant. Figure 11 depicts the intra-particle diffusion modelling, and as noticed, all processes presented multilinearity, indicating that two or more steps occurred during the adsorption processes. The first step corresponded to the external surface adsorption or instantaneous adsorption stage. The second step was characterized by a gradual adsorption stage, where the intra-particle diffusion was rate-controlled. The third step described the final equilibrium stage, where the intra-particle diffusion started to slow down due to the extremely low solute concentration in solution [36]. High yield external surface adsorption was only noticed at $\mathrm{pH} 3$; however, intraparticle adsorption can be clearly distinguished from 10 to $35 \mathrm{~min}^{1 / 2}$ for $\mathrm{pH} 3$ and 4 . Adsorption processes at $\mathrm{pH} 5$ showed intraparticle adsorption only after $35 \mathrm{~min}^{1 / 2}$, but above this $\mathrm{pH}$ adsorption processes adsorption did not show significant 
results during the studied time. The slopes for each $\mathrm{pH}$ and substrate per step are described as the rate parameter $k_{p, i}(\mathrm{i}=1-3)$ and listed in Table 5.

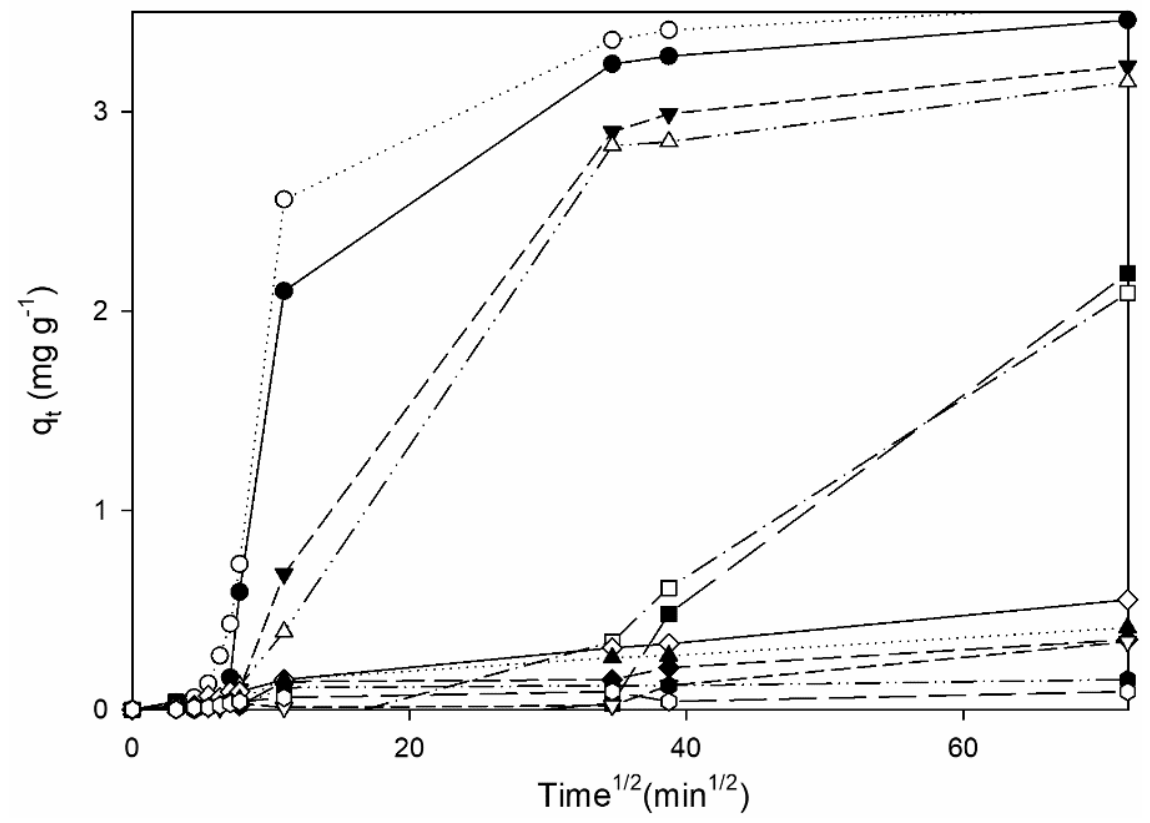

Figure 11. Intra-particle diffusion plot of CR adsorption for pH3 L1 (-๑); pH3 L2 $(\cdots \circ \cdots)$; pH4

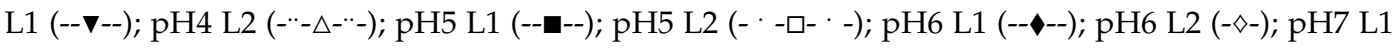

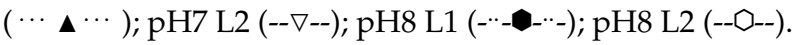

Table 5. Intra-particle diffusion data for different $\mathrm{pH}$ and two types of substrates.

\begin{tabular}{ccccccccccccc}
\hline \multirow{2}{*}{ Parameters } & \multicolumn{1}{c}{ L1 } & \multicolumn{1}{c}{ L2 } \\
\cline { 2 - 14 } & $\mathbf{p H 3}$ & $\mathbf{p H 4}$ & $\mathbf{p H 5}$ & $\mathbf{p H 6}$ & $\mathbf{p H 7}$ & $\mathbf{p H 8}$ & $\mathbf{p H 3}$ & $\mathbf{p H 4}$ & $\mathbf{p H 5}$ & $\mathbf{p H 6}$ & $\mathbf{p H 7}$ & $\mathbf{p H 8}$ \\
\hline$k_{p} 1$ & 0.003 & 0.002 & 0.002 & 0.006 & 0.003 & 0.002 & 0.021 & 0.002 & -0.014 & -0.008 & 0.003 & 0.003 \\
$k_{p} 2$ & 0.464 & 0.145 & 0.052 & 0.003 & 0.030 & 0.002 & 0.517 & 0.080 & 0.046 & 0.013 & -0.001 & 0.002 \\
$k_{p} 3$ & 0.006 & 0.008 & & 0.004 & 0.004 & 0.001 & 0.004 & 0.009 & & 0.007 & 0.007 & 0.001 \\
\hline
\end{tabular}

\subsection{Life Cycle}

Five adsorption cycles of five days each were carried out to determine the absorbance life cycle capacity of each filter. Figures 12 and 13 showed the percentage and appearance of dye removal in each cycle using the same filter without any cleaning or recovery procedure. As it can be seen, both types of filter showed efficiencies of more than $90 \%$ during the first three adsorption cycles. In both cases, cycles 4 and 5 revealed the limit of life cycle expectancy of the filters, probably indicating a saturation point of the filter material. Although both substrates presented similar behaviors, smaller particles (L2) presented a slightly higher adsorption yield probably due to their larger surface area compared to that of larger particles. 


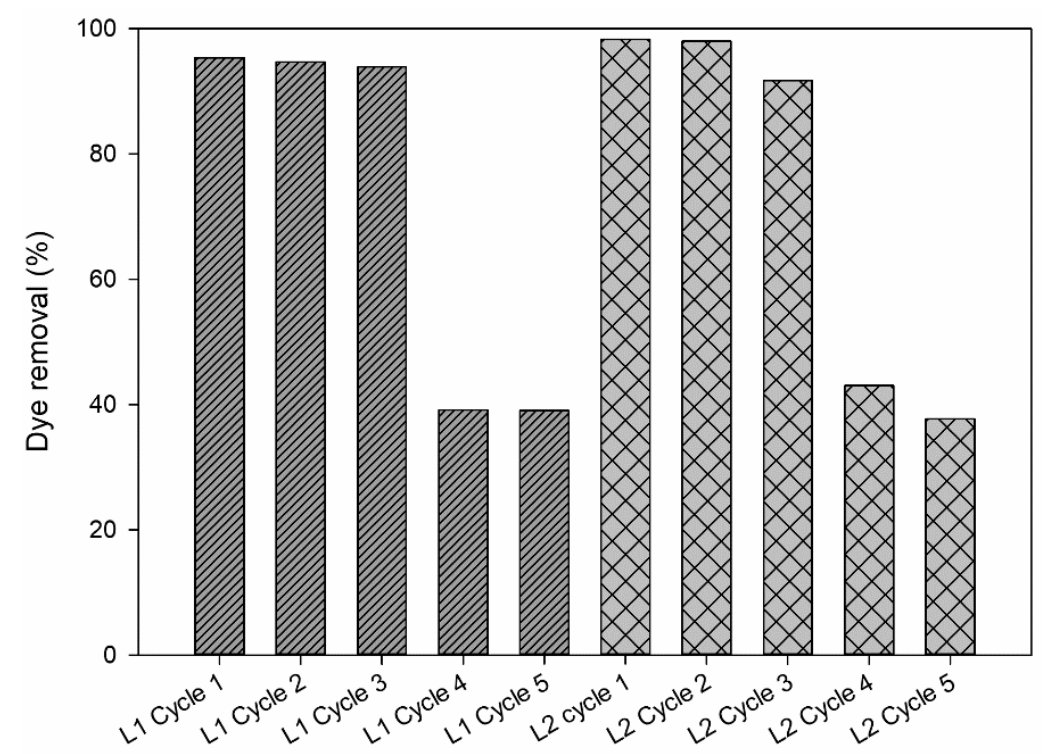

Figure 12. CR removed per cycle of APTES L1 and L2 adsorbents.
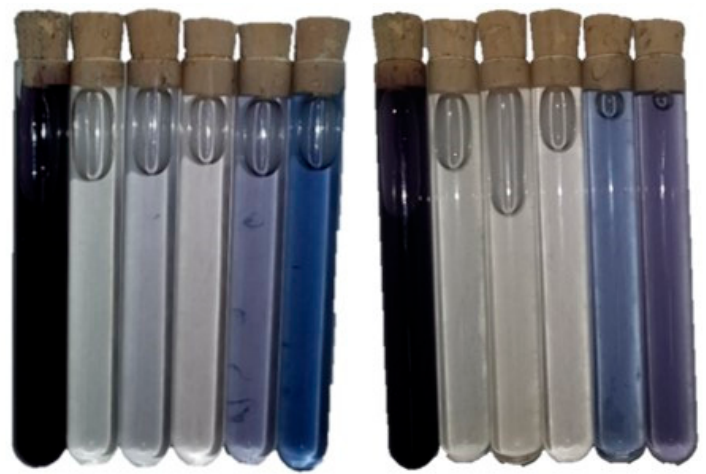

Figure 13. Dye removal process using APTES L1 (left group) and APTES L2 (right group) adsorbents. From left to right in each group: (A) Original Dye preparation, (B) water treated from cycle 1, (C) water treated from cycle 2, (D) water treated from cycle 3, (E) water treated from cycle 4 and (F) water treated from cycle 5 .

\subsection{Phytotoxicity}

Figure 14 shows the phytotoxicity property of the untreated and treated dye bath after dye absorption. These results were obtained from the measurement of sawgrass germination seeds exposed to water (control), the untreated dye bath, and the dye baths after being exposed to the adsorbents (treated dye baths). Seed germinated under treated dye baths grew significantly more than those exposed to the untreated dye baths. In general terms, there was no significant difference in terms of toxicity decrement between adsorbents with a smaller particle size (L2) than those with larger particle size (L1). However, the use of adsorbents clearly reduced the phytotoxicity of the dye baths, demonstrating not only a color removal, but also a reduction of the toxicity during the process. 


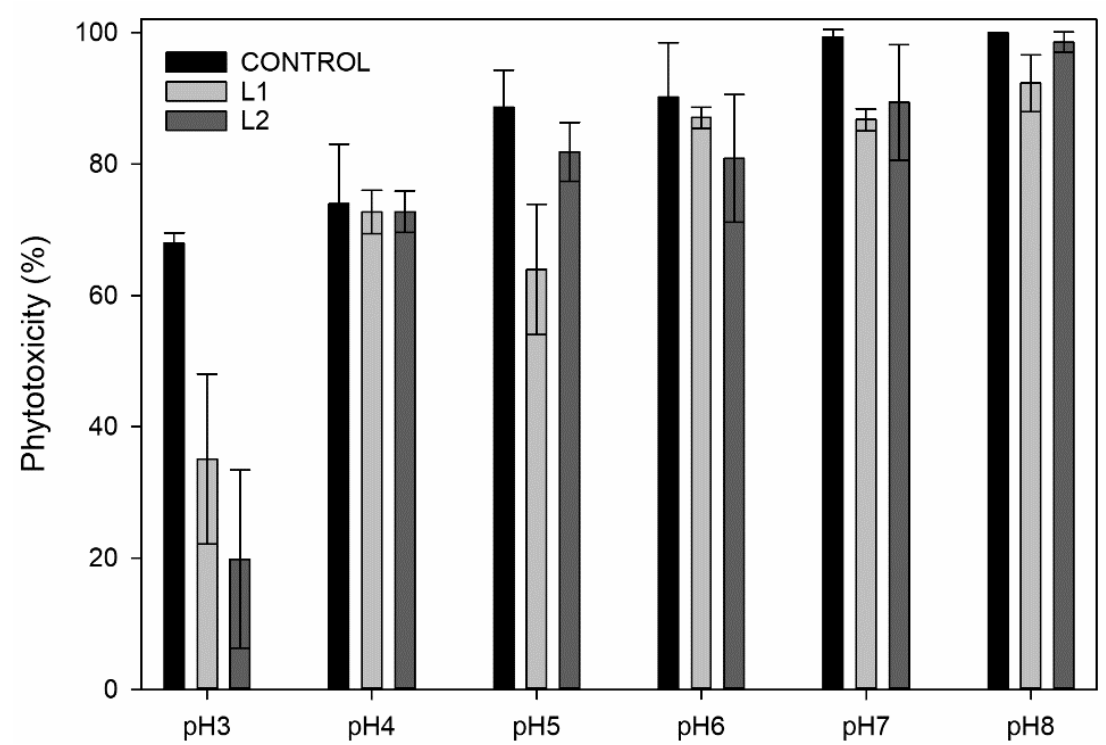

Figure 14. Percentage of phytotoxicity of the untreated and treated dye baths carried out at different pHs.

\subsection{SEM Photographs}

Figure 15 show SEM photographs of APTES L1 (top) and APTES L2 (bottom) before and after a dye bath exposure. As it can be noticed, the porosity of the material before exposure (a) was higher than that shown in the adsorbent materials after the dye bath exposure (b), confirming the adsorption process that took place. It can also be noticed that the smaller particle adsorbent (L2) presented a higher surface area than the adsorbent with a larger particle size (L1).

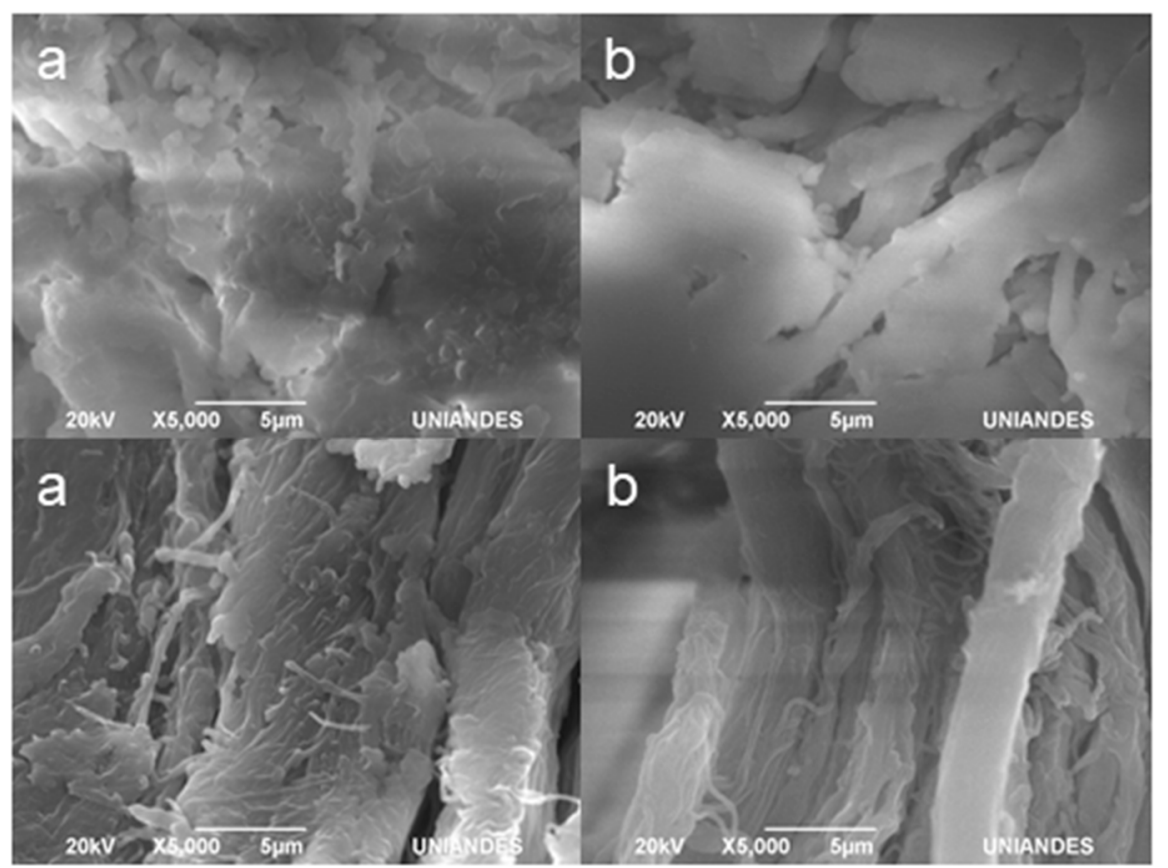

Figure 15. SEM photographs of APTES L1 (Top) and L2 (Bottom) before (a) and after (b) dye exposure.

\section{Conclusions}

Functionalized solid hazardous waste from the leather industry was used as an adsorbent for the removal of organic contaminant from aqueous solutions. Different types of functionalizations were tested and the two most promising ones were selected in order to determine the ability of removal 
at different $\mathrm{pH}$. Their potential to adsorb anionic dye was higher at low $\mathrm{pH}$, also in agreement with reductions up to $50 \%$ in the phytotoxicity of the remaining treated dye bath. The results obtained showed a very promising use in the removal of dyes under acidic conditions, and moreover, it demonstrates the possibility to use the waste leather from the footwear and textile industry to treat the dye baths used as a supply for the same industries. These results support, in principle, the use of these hazardous residues, especially in countries with a large leather tanning industry that are also related to the presence of high yields of wastewater containing dyes and a poor disposition of residual tanned leather.

Author Contributions: Conceptualization, C.C. and J.F.O.; methodology, C.C. and J.F.O.; software, C.C. and J.F.O.; validation, C.C. and J.F.O.; formal analysis, C.C. and J.F.O.; investigation, C.C.; resources, C.C. and J.F.O.; data curation, C.C. and J.F.O.; writing-original draft preparation, C.C. and J.F.O.; writing-review and editing, C.C. and J.F.O.; visualization, C.C. and J.F.O.; supervision, C.C. and J.F.O.; project administration, J.F.O.; funding acquisition, J.F.O.

Funding: This research received no external funding.

Acknowledgments: The authors want to thank Industrias Wilches S.A. (Colombia) for providing the residual leather from footwear and some of the reagents for the surface functionalization. Also, the authors thank the Clean Room laboratory of the Department of Electrical and Electronic Engineering for the use of their facilities and the Center of Microscopy of Universidad de los Andes for the acquisition of SEM images.

Conflicts of Interest: The authors declare no conflict of interest.

\section{References}

1. Rosari, S.; Ardiansyah, T. Degradation of Methylene Blue and Congo-Red Dyes Using Fenton, PhotoFenton, Sono-Fenton, and Sonophoto-Fenton Methods in the Presence of Iron (II, III) Oxide/Zinc Oxide/Graphene (Fe3O4/ZnO/Graphene) Composites. Sep. Purif. Technol. 2019, 210, 563-573. [CrossRef]

2. Prabhu, S.M.; Khan, A.; Hasmath Farzana, M.; Hwang, G.C.; Lee, W.; Lee, G. Synthesis and Characterization of Graphene Oxide-Doped Nano-Hydroxyapatite and Its Adsorption Performance of Toxic Diazo Dyes from Aqueous Solution. J. Mol. Liq. 2018, 269, 746-754. [CrossRef]

3. Altermatt, F.; Joss, A.; Eggen, R.I.L.; Stamm, C.; Reyes, M.; Räsänen, K.; Focks, A.; Munz, N.A.; Burdon, F.J. Agriculture versus Wastewater Pollution as Drivers of Macroinvertebrate Community Structure in Streams. Sci. Total Environ. 2018, 659, 1256-1265. [CrossRef]

4. Guilherme, L.R.G.; Oliveira, L.C.A.; Dallago, R.M.; Guerreiro, M.C.; Oliveira, D.Q.L.; Gonçalves, M. Solid Waste from Leather Industry as Adsorbent of Organic Dyes in Aqueous-Medium. J. Hazard. Mater. 2006, 141, 344-347. [CrossRef]

5. Lavanya, C.; Soontarapa, K.; Jyothi, M.S.; Balakrishna, R.G. Environmental Friendly and Cost Effective Caramel for Congo Red Removal, High Flux, and Fouling Resistance of Polysulfone Membranes. Sep. Purif. Technol. 2019, 211, 348-358. [CrossRef]

6. Etemadinia, T.; Behnam, B.; Allahresani, A. Removal of Congo Red Dye from Aqueous Solutions Using Znfe2o4/Sio2 Tragacanth Gum Magnetic Nanocomposite as a Novel Adsorbent, Surfaces and Interfaces. Surf. Interfaces 2019, 14, 117-126. [CrossRef]

7. Liu, J.; Wang, N.; Zhang, H.; Baeyens, J. Adsorption of Congo Red Dye on FexCo3-XO4 Nanoparticles. J. Environ. Manag. 2019, 238, 473-483. [CrossRef] [PubMed]

8. Chen, M.; Wu, P.; Yu, L.; Liu, S.; Ruan, B.; Hu, H.; Zhu, N.; Lin, Z. FeOOH-Loaded MnO2 Nano-Composite: An Efficient Emergency Material for Thallium Pollution Incident. J. Environ. Manag. 2017, 192, 31-38. [CrossRef]

9. Selcuk, H. Decolorization and Detoxification of Textile Wastewater by Ozonation and Coagulation Processes. Dye. Pigment. 2005, 64, 217-222. [CrossRef]

10. Robati, D.; Rajabi, M.; Moradi, O.; Najafi, F.; Tyagi, I.; Agarwal, S.; Gupta, V.K. Kinetics and Thermodynamics of Malachite Green Dye Adsorption from Aqueous Solutions on Graphene Oxide and Reduced Graphene Oxide. J. Mol. Liq. 2016, 214, 259-263. [CrossRef]

11. Lee, Y.-C.; Kim, E.J.; Yang, J.-W.; Shin, H.-J. Removal of Malachite Green by Adsorption and Precipitation Using Aminopropyl Functionalized Magnesium Phyllosilicate. J. Hazard. Mater. 2011, 192, 62-70. [CrossRef] [PubMed] 
12. Saeed, A.; Sharif, M.; Iqbal, M. Application Potential of Grapefruit Peel as Dye Sorbent: Kinetics, Equilibrium and Mechanism of Crystal Violet Adsorption. J. Hazard. Mater. 2010, 179, 564-572. [CrossRef] [PubMed]

13. Magdy, A.; Fouad, Y.O.; Abdel-Aziz, M.H.; Konsowa, A.H. Synthesis and Characterization of Fe3O4/Kaolin Magnetic Nanocomposite and Its Application in Wastewater Treatment. J. Ind. Eng. Chem. 2017, 56, 299-311. [CrossRef]

14. Koyuncu, I. Reactive Dye Removal in Dye/Salt Mixtures by Nanofiltration Membranes Containing Vinylsulphone Dyes: Effects of Feed Concentration and Cross Flow Velocity. Desalination 2002, 143, 243-253. [CrossRef]

15. Lee, J.-W.; Choi, S.-P.; Thiruvenkatachari, R.; Shim, W.-G.; Moon, H. Submerged Microfiltration Membrane Coupled with Alum Coagulation/Powdered Activated Carbon Adsorption for Complete Decolorization of Reactive Dyes. Water Res. 2006, 40, 435-444. [CrossRef] [PubMed]

16. Qi, L.; Yu, J.; Jaroniec, M. Enhanced and Suppressed Effects of Ionic Liquid on the Photocatalytic Activity of TiO2. Adsorption 2013, 19, 557-561. [CrossRef]

17. Lemlikchi, W.; Drouiche, N.; Belaicha, N.; Oubagha, N.; Baaziz, B.; Mecherri, M.O. Kinetic Study of the Adsorption of Textile Dyes on Synthetic Hydroxyapatite in Aqueous Solution. J. Ind. Eng. Chem. 2015, 32, 233-237. [CrossRef]

18. Mahmoud, M.E.; Abdou, A.E.H.; Shehata, A.K.; Header, H.M.A.; Hamed, E.A. Sustainable Super Fast Adsorptive Removal of Congo Red Dye from Water by a Novel Technique Based on Microwave-Enforced Sorption Process. J. Ind. Eng. Chem. 2018, 57, 28-36. [CrossRef]

19. Purkait, M.; Maiti, A.; DasGupta, S.; De, S. Removal of congo red using activated carbon and its regeneration. J. Hazard. Mater. 2007, 145, 287-295. [CrossRef]

20. Omidi Khaniabadi, Y.; Mohammadi, M.; Shegerd, M.; Sadeghi, S.; Basiri, H. Removal of Congo red dye from aqueous solutions by a low-cost adsorbent: Activated carbon prepared from Aloe vera leaves shell. Environ. Health Eng. Manag. 2016, 4, 29-35. [CrossRef]

21. Reddy, M.S.; Sivaramakrishna, L.; Reddy, A.V. The use of an agricultural waste material, Jujuba seeds for the removal of anionic dye (Congo red) from aqueous medium. J. Hazard. Mater. 2011, 203-204, 118-127.

22. Wanyonyi, W.C.; Onyari, J.M.; Shiundu, P.M. Adsorption of Congo Red Dye from Aqueous Solutions Using Roots of Eichhornia Crassipes: Kinetic and Equilibrium Studies. Energy Procedia 2014, 50, 862-869. [CrossRef]

23. Khaniabadi, Y.O.; Basiri, H.; Nourmoradi, H.; Mohammadi, M.J.; Yari, A.R.; Sadeghi, S.; Amrane, A. Adsorption of Congo Red Dye from Aqueous Solutions by Montmorillonite as a Low-Cost Adsorbent. Int. J. Chem. React. Eng. 2018, 16. [CrossRef]

24. Kneip, M.; Danisch, P. Water Repellent Treatment of Leather and Skins with Polysiloxanes Functionalized with Carboxyl Groups in a Comb-like Manner. United States patent US 5,702,490, 6 February 1995.

25. Bay, H.; Eckert, G.; Bergold, W. Hydrophobization of Leather, Pelts and Leather Substitute Materials with Carboxyl-Containing Polysiloxanes. United States patent US 4,931,062, 10 January 1989.

26. Li, G.; Yan, J.; Yan, W. Aqueous Polyurethane Leather Finishing and Preparation Method. CN 102,796,447, 12 July 2012.

27. Pan, H.; Li, G.L.; Liu, R.Q.; Wang, S.X.; Wang, X.D. Preparation, Characterization and Application of Dispersible and Spherical Nano-SiO2@Copolymer Nanocomposite in Leather Tanning. Appl. Surf. Sci. 2017, 426, 376-385. [CrossRef]

28. Carvalho, I.; Ferdov, S.; Mansilla, C.; Marques, S.M.; Cerqueira, M.A.; Pastrana, L.M.; Henriques, M.; Gaidau, C.; Ferreira, P.; Carvalho, S. Development of Antimicrobial Leather Modified with Ag-TiO2 Nanoparticles for Footwear Industry. Sci. Technol. Mater. 2018, 30, 60-68. [CrossRef]

29. Yang, J.; Luo, X.; Yan, T.; Lin, X. Recovery of Cesium from Saline Lake Brine with Potassium Cobalt Hexacyanoferrate-Modified Chrome-Tanned Leather Scrap Adsorbent. Coll. Surf. A Physicochem. Eng. Asp. 2018, 537, 268-280. [CrossRef]

30. Lladó, J.; Gil, R.R.; Lao-Luque, C.; Solé-Sardans, M.; Fuente, E.; Ruiz, B. Highly Microporous Activated Carbons Derived from Biocollagenic Wastes of the Leather Industry as Adsorbents of Aromatic Organic Pollutants in Water. J. Environ. Chem. Eng. 2017, 5, 2090-2100. [CrossRef]

31. Sarkar, A.; Daniels-Race, T. Electrophoretic Deposition of Carbon Nanotubes on 3-Amino-PropylTriethoxysilane (APTES) Surface Functionalized Silicon Substrates. Nanomaterials 2013, 3, 272-288. [CrossRef]

32. Syga, Ł.; Spakman, D.; Punter, C.; Poolman, B. Method for immobilization of living and synthetic cells for high-resolution imaging and single-particle tracking. Sci. Rep. 2018, 8, 13789. [CrossRef] 
33. Rehman, R.; Song, Q.; Peng, L.; Chen, Y.; Gu, X. Hydrophobic modification of SAPO-34 membranes for improvement of stability under wet condition. Chin. J. Chem. Eng. 2019. [CrossRef]

34. Pingan, H.; Mengjun, J.; Yanyan, Z.; Ling, H. A silica/PVA adhesive hybrid material with high transparency, thermostability and mechanical strength. RSC Adv. 2017, 7, 2450-2459. [CrossRef]

35. Osma, J.F.; Saravia, V.; Toca-Herrera, J.L.; Couto, S.R. Sunflower Seed Shells: A Novel and Effective Low-Cost Adsorbent for the Removal of the Diazo Dye Reactive Black 5 from Aqueous Solutions. J. Hazard. Mater. 2007, 147, 900-905. [CrossRef] [PubMed]

36. Jagusiak, A.; Pańczyk, T. Interaction of Congo Red, Evans Blue and Titan Yellow with Doxorubicin in Aqueous Solutions. A Molecular Dynamics Study. J. Mol. Liq. 2019, 279, 640-648. [CrossRef]

37. Weber, W.; Morris, J. Advances in Water Pollution Research: Removal of Biologically Resistant Pollutant from Waste Water by Adsorption. In International Conference on Water Pollution Symposium; Pergamon: Oxford, UK, 1962; pp. 231-266.

(C) 2019 by the authors. Licensee MDPI, Basel, Switzerland. This article is an open access article distributed under the terms and conditions of the Creative Commons Attribution (CC BY) license (http://creativecommons.org/licenses/by/4.0/). 